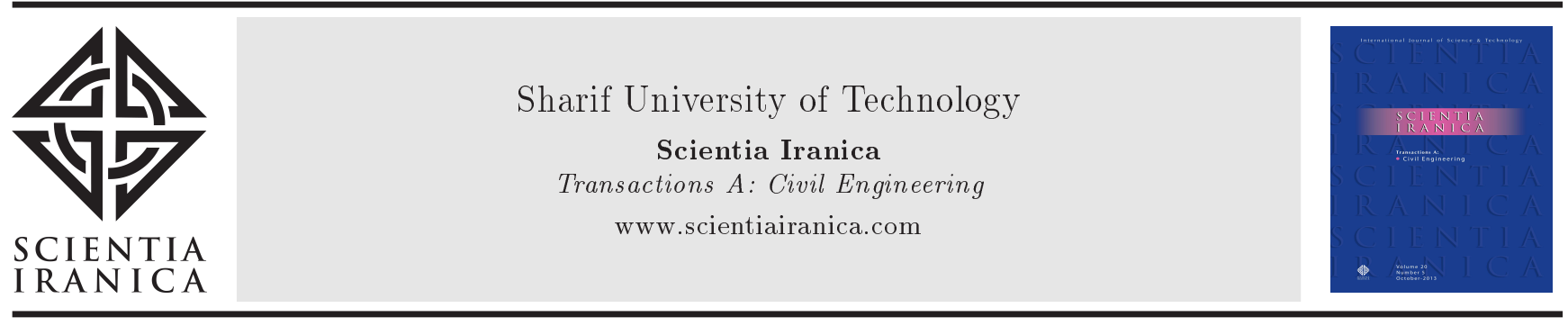

\title{
Evaluation of the static and seismic active lateral earth pressure for $c-\phi$ soils by the ZEL method
}

\author{
A. Keshavarz* and Z. Pooresmaeil \\ School of Engineering, Persian Gulf University, Bushehr, Iran.
}

Received 9 November 2014; received in revised form 11 April 2015; accepted 2 June 2015

\section{KEYWORDS}

Zero extension lines;

Static;

Seismic;

Active;

Lateral earth pressure;

Retaining walls;

Non-associated.

\begin{abstract}
The method of Zero Extension Lines (ZEL) has been used to evaluate the static and seismic active lateral earth pressure on an inclined wall retaining $c-\phi$ backfill. The equilibrium equations along the zero extension lines have been solved using the finite difference method. A computer code is prepared to analyze the retaining wall, calculate the ZEL network and the distribution of the active lateral earth pressure behind the retaining wall. The total active force on the retaining wall was defined as the lateral earth pressure coefficients due to the soil unit weight, the surcharge, and the soil cohesion. The variations of the active lateral earth pressure coefficients with changes in different parameters, such as the inclination of the earth and wall, the friction angle of the soil, the adhesion of the soil-wall interface, the horizontal and vertical pseudo-static earthquake coefficients, have been obtained. The results have been obtained for soils with associated and non-associated flow rules. The effect of the dilation angle has also been considered. The results obtained in this study are very close to those of other methods and confirm that the ZEL method can be successfully used to evaluate the lateral earth pressure of retaining walls.
\end{abstract}

(C) 2016 Sharif University of Technology. All rights reserved.

\section{Introduction}

Many different methods are provided to evaluate the active lateral earth pressure on the retaining wall. Rankin and Coulomb are the common methods. Stress characteristics $[1,2]$ or slip lines method, limit analysis method [3,4], Rankine's conjugate stress concept [5], and slice analysis method [6] are also used to evaluate the lateral earth pressure. Zero Extension Lines (ZEL) method is one of the methods that is capable of analyzing the stability of retaining walls under general conditions in static and seismic conditions. This method was first used by Roscoe [7] to solve static and dynamic problems of retaining walls. In 1971, James and Bransby [8] used ZEL method to

*. Corresponding author. Tel/Fax: +98 r7 33440376

E-mail addresses: keshavarz@pgu.ac.ir; and

amin_keshavarz@yahoo.com (A. Keshavarz);

zahra.pouresmael@gmail.com (Z.Pooresmaeil) predict the strain patterns behind retaining walls. Habibagahi and Ghahramani [9] presented an earth pressure theory based on the simple ZEL field to predict stress patterns in the backfill behind a vertical wall. Anvar and Ghahramani [10] derived the equilibrium equations along the ZEL and presented the application of ZEL method. Jahanandish [11] developed a theory regarding the ZEL method and derived the equilibrium equations along zero extension lines for axial symmetry. Furthermore, ZEL method has also been used to study the stability of slopes [12], analyze three-dimensional stability of soils [13], predict the behavior of dense frictional soils [14], and evaluate bearing capacity of soils and foundations and dynamic lateral pressure of retaining structures [15-17]. Veiskarami et al. [18-20] used this method to predict the bearing capacity of foundations and load-displacement behavior of shallow foundations considering the stress level effect.

Many available methods evaluate lateral earth pressure on the retaining walls by using the assumption 
of the associated flow rule, although 'Real' soils have a non-associated flow rule and the dilation angle is smaller than the friction angle [21]. One of the advantages of ZEL method is that in this method, soil can be associative or non-associative. Therefore, by using the ZEL method, the effect of the dilation angle can be evaluated. Lee and Herington [22] evaluated the passive earth pressures for non-associated flow rules by a theoretical study. Shiau and Smith [23] studied, numerically, the effect of non-associated flow rule on the passive earth pressure. Benmeddour et al. [21] provided passive and active lateral earth pressure coefficients due to the soil unit weight for the soil with dilation angle equal to zero. They studied the influence of non-associativity by a numerical method and modifying values of the soil friction angle and cohesion.

Moreover, ZEL method does not have the limitation of assuming the shape of the rupture surface. By using this method, the failure zone is determined after analyzing the retaining wall. ZEL method analyzes geotechnical problems in the strain field. When the soil is assumed as associative soil, i.e. the friction angle of the soil is equal to its dilation angle, ZEL method is similar to the stress characteristics or slip lines method.

The ZEL method has been used in this paper to evaluate the seismic stability of retaining walls for nonassociated and associated flow rules and propose the lateral earth pressure coefficients. Although Habibagahi and Ghahramani [9] developed the ZEL for static lateral earth pressure, they used the simple ZEL filed and developed the method for sands. This study develops the ZEL method for the active lateral earth pressure for $c-\phi$ soils in seismic case. Consideration of the effect of different parameters of the soil and retaining wall, especially the soil dilation angle, is one of the advantages of this study. Also, the lateral earth pressure coefficients due to the soil unit weight, surcharge, and soil cohesion have been provided for non-associative soil.

\section{Theory}

The geometry of the retaining wall in the active case has been shown in Figure 1(a). The surcharge $q$ is applied on the ground surface. The ground surface makes an angle $\beta$ with the horizontal direction and the wall angle with the vertical direction is $\theta$. The height of the retaining wall is $H$. The positive directions of the $\beta$ and $\theta$ are shown in Figure 1(a).

\subsection{Assumptions}

1. The backfill soil is considered as a $c-\phi$ soil and follows the Mohr-Coulomb yield criterion, where $c$ is the cohesion in $\mathrm{kPa}$ and $\phi$ is the internal friction angle in degree;
2. The unit weight of the soil mass is assumed equal to $\gamma$ in $\mathrm{kN} / \mathrm{m}^{3}$;

3. The friction angle in the interface between soil and wall is considered as $\delta_{w}$ in degree;

4. The adhesion of the soil-wall interface is assumed $c_{w}$ in $\mathrm{kPa}$;

5. The principle of superposition is valid for static and seismic analyses;

6. The retaining wall problem is considered plane strain and two dimensional.

\subsection{Boundary conditions}

Analyzing the problem requires knowing the boundary conditions along the ground surface and the retaining wall. The boundary conditions are explained in the following sections.

\subsubsection{Along the ground surface}

To calculate the coordinates $(x, z)$ of the points on the ground surface, a length of $L$ is considered on this boundary and it is divided into $n$ divisions. According to Figure 1(a), the coordinates of the point number $i$ on the ground surface can be calculated as:

$$
x_{i}=-\frac{L}{n}(i-1) \cos \beta, \quad z_{i}=x_{i} \tan \beta,
$$

where $\beta$ is the ground angle with horizontal direction. As mentioned before, the vertical stress $q$ is applied on the ground surface. So, the normal and shear stresses for the points on the ground are obtained as:

$$
\begin{aligned}
& \sigma_{0}=q \cos \beta\left[\left(1-k_{v}\right) \cos \beta-k_{h} \sin \beta\right], \\
& \tau_{0}=q \cos \beta\left[\left(1-k_{v}\right) \sin \beta+k_{h} \cos \beta\right],
\end{aligned}
$$

where $k_{h}$ and $k_{v}$ are horizontal and vertical pseudostatic earthquake coefficients.

The Mohr circle of stress on the ground can be shown in Figure 1(b). The average stress on the ground $\left(p_{0}\right)$ is obtained from the Mohr circle:

$$
\begin{aligned}
& p_{0}= \\
& \frac{\sigma_{0}+c \cos \phi \sin \phi-\sqrt{\left(\sigma_{0} \sin \phi+c \cos \phi\right)^{2}-\left(\tau_{0} \cos \phi\right)^{2}}}{\cos ^{2} \phi} .
\end{aligned}
$$

Using the Mohr circle of stress, the angle $\psi$ (the angle between $\varepsilon_{1}$ and the horizontal axis) on the ground surface $\left(\psi_{0}\right)$ can also be calculated as:

$$
\begin{aligned}
& \text { if } q=0: \psi_{0}=\beta+\frac{\pi}{2} \\
& \text { else } \psi_{0}=\frac{\pi}{2}+0.5\left[\beta-\delta-\sin ^{-1}\left(\frac{p_{0} \sin (\delta+\beta)}{R_{0}}\right)\right]
\end{aligned}
$$

where:

$$
\tan \delta=\frac{k_{h}}{1-k_{v}}, \quad R_{0}=p_{0} \sin \phi+c \cos \phi .
$$




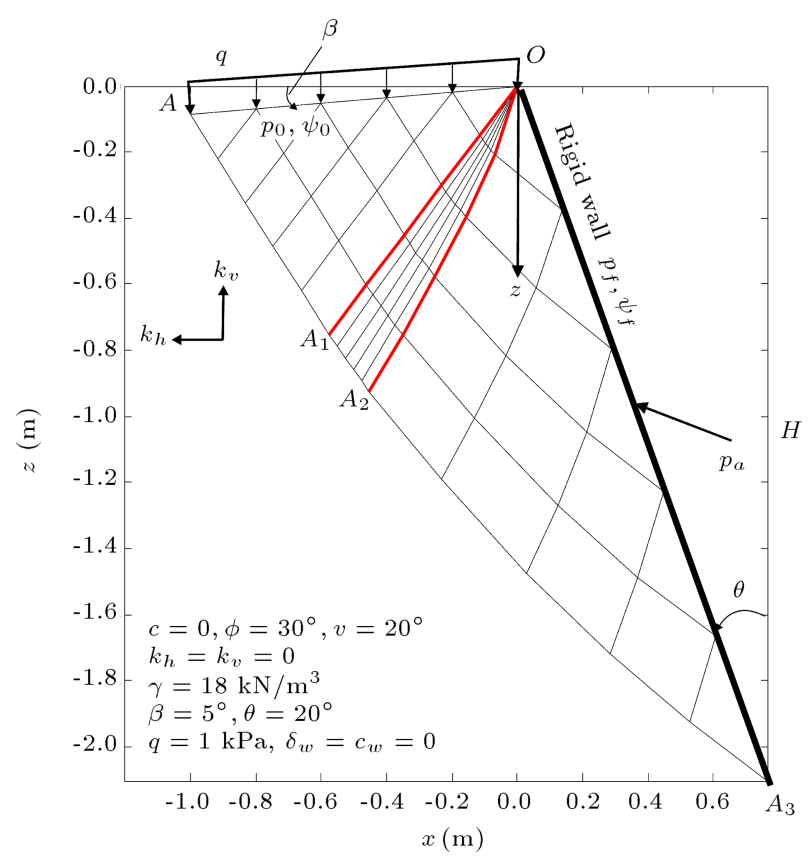

(a)

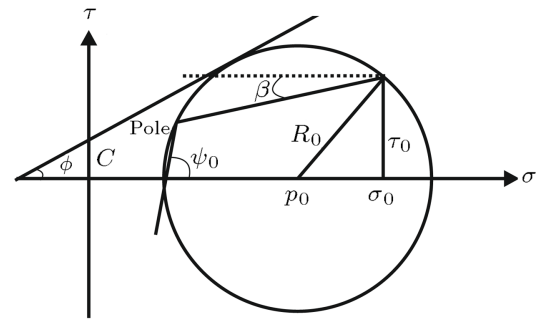

(b)

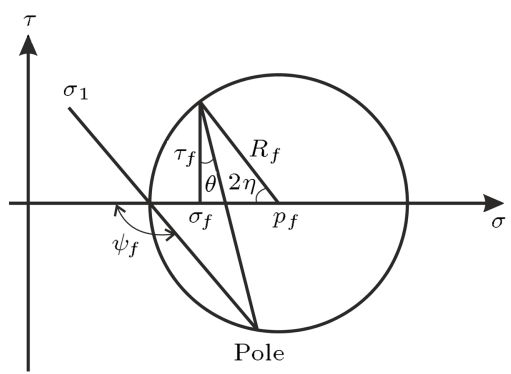

(c)

Figure 1. The retaining wall problem: (a) Geometry and ZEL network; (b) boundary condition along the ground surface; and (c) boundary condition along the retaining wall.

\subsubsection{Along the retaining wall}

Assuming the normal and shear stresses on the retaining wall, the Mohr circle of stress on this boundary is shown in Figure 1(c). The following equations are derived from this figure:

$$
\begin{aligned}
& \psi_{f}=\frac{\pi}{2}+\eta+\theta, \\
& \sigma_{f}=p_{f}-R_{f} \cos 2 \eta_{f}, \\
& \tau_{f}=c_{w}+\sigma_{f} \tan \delta_{w},
\end{aligned}
$$

where $\sigma_{f}$ and $\tau_{f}$ are the normal and shear stresses on the retaining wall, respectively. Then, the angle $\psi$ on the wall $\left(\psi_{f}\right)$ can be calculated from Eq. (6):

$$
\begin{aligned}
\psi_{f}= & \frac{\pi}{2}+\theta \\
& +0.5\left[-\delta_{w}+\sin ^{-1}\left(\frac{p_{f} \sin \delta_{w}+c_{w} \cos \delta_{w}}{p_{f} \sin \phi+\cos \phi}\right)\right] .
\end{aligned}
$$

\subsection{Equilibrium equations along the zero extension lines}

By considering the soil shearing in a principal plane for plane strain problem, major and minor principal strain increments do not have the same concept. Therefore, two lines (AP and BP) in the soil element will have the linear strains equal to zero in their directions (Figure 2). AP and BP are called the zero extension lines in minus direction $\left(\mathrm{ZEL}^{-}\right)$and plus direction $\left(\mathrm{ZEL}^{+}\right)$, respectively.

Each point in the soil has four features, $x, z$, $p$, and $\psi$. By solving the equations along the zero extension lines, these features can be determined. As illustrated in Figure 2, the angle between zero extension lines is $\pi / 2-v$, where $v$ is the dilation angle of the soil. The angle of zero extension lines with $x$ axis is $\psi \pm \zeta$. Angle $\zeta$ is defined as follows:

$$
\zeta=\frac{\pi}{4}-\frac{v}{2} \text {. }
$$

Therefore, the slope of these lines is expressed as: 

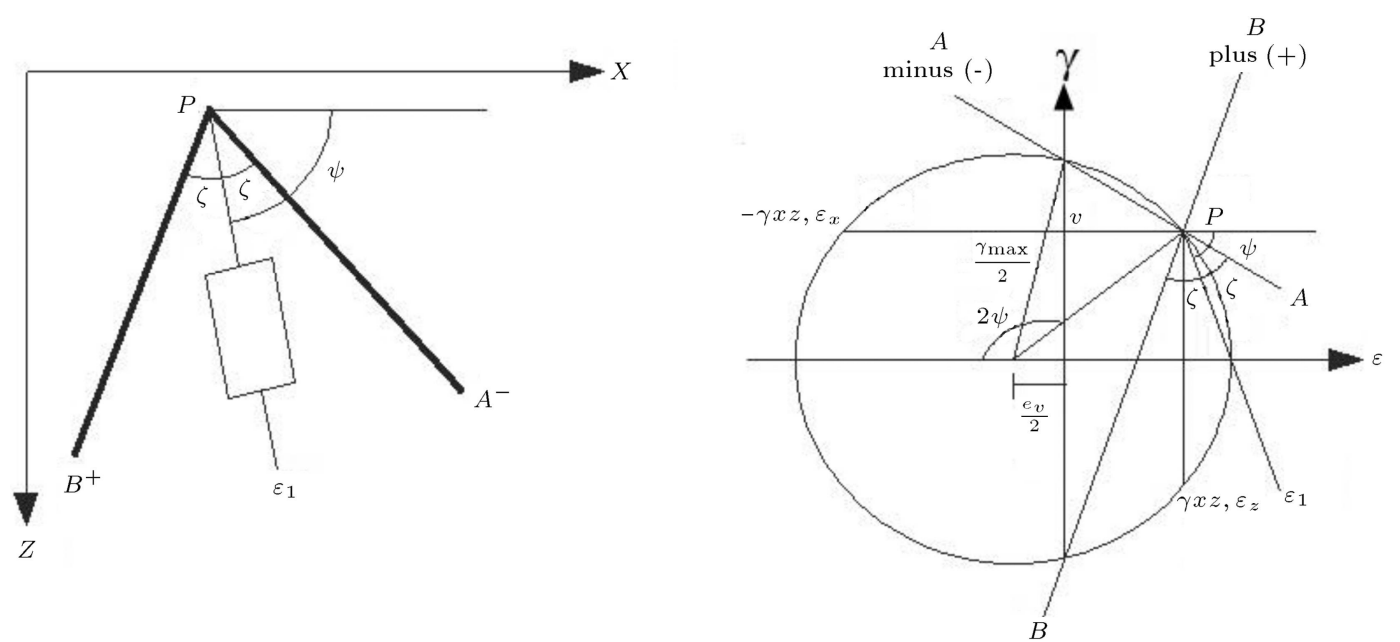

Figure 2. The directions of zero extension lines and Mohr circle of the strain [10].

Plus ZEL, PB : $\frac{d z}{d x}=\tan (\psi+\zeta)$,

Minus ZEL, PB : $\frac{d z}{d x}=\tan (\psi-\zeta)$.

The equilibrium equations along the plus and minus zero extension lines can be written as [10]:

$$
\begin{aligned}
d p & +2(p \tan \phi+c)\left[\bar{\alpha} d \psi+\bar{\zeta} \frac{\partial \psi}{\partial \varepsilon^{-}} d \varepsilon^{+}\right] \\
& =f_{x} \bar{\beta}(\bar{\alpha} d x-\tan \phi d z)+f_{z} \bar{\beta}(\tan \phi d x+\bar{\alpha} d z)
\end{aligned}
$$

and along the plus ZEL:

$$
\begin{aligned}
d p & -2(p \tan \phi+c)\left[\bar{\alpha} d \psi+\bar{\zeta} \frac{\partial \psi}{\partial \varepsilon^{+}} d \varepsilon^{-}\right] \\
& =f_{x} \bar{\beta}(\bar{\alpha} d x-\tan \phi d z)+f_{z} \bar{\beta}(\tan \phi d x+\bar{\alpha} d z),
\end{aligned}
$$

where $f_{x}$ and $f_{z}$ are body forces along the $x$ and $z$ axes which are defined as $-\gamma k_{h}$ and $-\gamma\left(1-k_{v}\right) ; d \varepsilon^{+}$and $d \varepsilon^{-}$are the length of the plus and minus zero extension lines, respectively, and:

$$
\begin{aligned}
& \bar{\alpha}=\frac{1-\sin v \sin \phi}{\cos v \cos \phi}, \\
& \bar{\beta}=\frac{\cos v}{\cos \phi}, \\
& \bar{\zeta}=\frac{\sin \phi-\sin v}{\cos \phi \cos v} .
\end{aligned}
$$

If $x, z, p$, and $\psi$ of points $A$ and $B$ are known, these values of any point $P$ can be found by writing Eqs. (9)(12) in the finite difference form:

$$
x_{P}=\frac{Z_{A}-Z_{B}-x_{A} \operatorname{tgmm}+x_{B} \operatorname{tgmp}}{\operatorname{tgmp}-\operatorname{tgmm}},
$$

$$
\begin{aligned}
& z_{P}=\left(x_{C}-x_{B}\right) \operatorname{tgmp}+z_{B}, \\
& p_{P}=p_{B}+A_{1}-B_{m p}\left(\psi_{C}-\psi_{B}\right), \\
& \psi_{P}=\frac{A_{3}}{A_{4}} .
\end{aligned}
$$

The parameters in Eqs. (14)-(17) are defined in the appendix. By using the trial-and-error procedure, a function is written in MATLAB to calculate the unknown parameters $(x, z, p$, and $\psi$ ) of point $P$. First, it is assumed that these parameters are equal to the parameters of points $A$ and $B$ on the minus and plus ZEL, respectively. Then, the new parameters of point $P$ can be calculated using Eqs. (14)-(17). This procedure is repeated until the difference between the new and old parameters of point $P$ is small enough.

\subsection{ZEL networks}

A computer code in MATLAB is provided to analyze the problem. The code starts the calculation from the ground surface. The calculation continues to determine the characteristics of the points on the retaining wall. Three different types of ZEL network can arise according to the magnitudes of $\psi_{0}$ and $\psi_{f}$ (Figure 3).

Type $1, \psi_{f}=\psi_{0}$ : In this case, the ZEL network includes Rankin and mixed zones. First, the points in Rankin zone are solved by using the boundary conditions on the ground surface and equilibrium equations along the ZEL lines. Then, the network in the mixed zone is determined knowing the information on line $\mathrm{OA}_{2}$ and the boundary conditions along the retaining wall.

Type 2, $\psi_{\boldsymbol{f}}>\psi_{\mathbf{0}}$ : In this case, the ZEL network includes three zones: Rankin, Goursat, and mixed. 


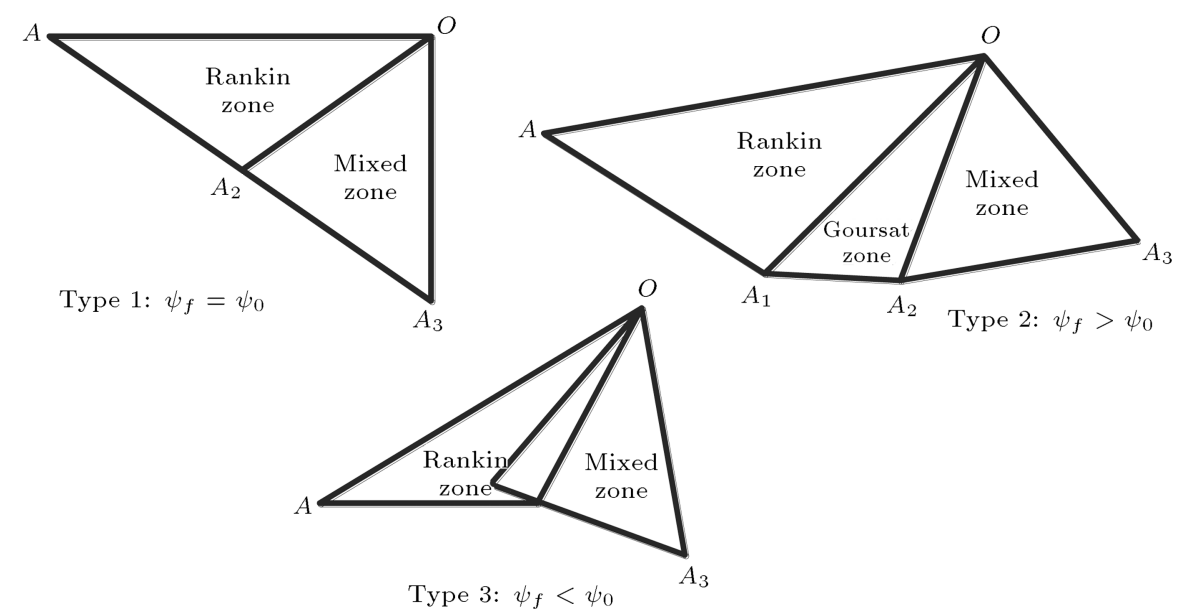

Figure 3. Different types of ZEL networks.
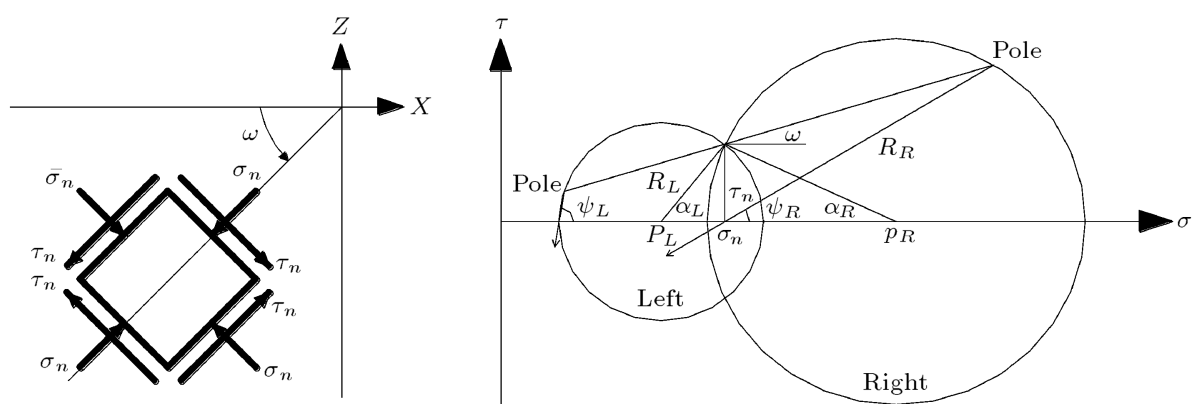

Figure 4. The soil element on the stress discontinuity line and Mohr circle.

First, the points in Rankin zone are solved by using the boundary conditions on the ground surface and equilibrium equations along the ZEL lines. Now, the relation between $\psi$ and $p$ should be obtained to solve the points in Goursat zone. The $p$ and $\psi$ in the left and right of point $O$ (Figure 1) are different and a singularity exists at this point.

Therefore, at point $O, d x=d z=0$, and the relation between $\psi$ and $p$ is determined from Eq. (11) as:

$$
\begin{gathered}
\text { if } \phi \neq 0, \quad p=-c \cot \phi+\left(p_{0}+c \cot \phi\right) \exp \\
{\left[-\frac{2 \sin \phi}{\cos v}\left(\psi-\psi_{0}\right)\right],} \\
\text { if } \phi=0, \quad p=-\frac{2 c}{\cos v}\left(\psi-\psi_{0}\right)+p_{0} .
\end{gathered}
$$

Then, the Goursat zone is determined by using the information at the singularity point (point $O$ in Figure 1) and line $O A_{1}$. Finally, the mixed zone is obtained similar to Type 1 problem.

Type 3, $\psi_{\boldsymbol{f}}<\psi_{\mathbf{0}}$ : In this case, the Goursat zone will be removed similar to Type 1 problem and the Rankin and mixed zone will be wrapped. So, a stress discontinuity happens in the stress field and should be solved. Lee and Herington [22] provided an algorithm to solve the stress discontinuity. In this study, in order to solve the stress discontinuity, the Lee and Heringtion [22] method has been modified.

An element of the soil has been considered on the discontinuity line (see Figure 4). According to the Mohr circle, shown in Figure 4, the direction of the discontinuity line can be calculated as:

$$
\omega=0.5\left[\psi_{R}+\psi_{L}-\cos ^{-1}\left(\sin \phi \cos \left(\psi_{R}-\psi_{L}\right)\right)\right],
$$

where, $\omega$ is the direction of the discontinuity line and $\psi_{R}$ and $\psi_{L}$ are the angle $\psi$ related to the right and left sides of the discontinuity line, respectively.

Knowing the left side characteristics of the singularity point $O$ (the values on the earth for the first step) and from Eq. (19), the first direction $\left(\omega_{0}\right)$ is obtained and the intersection between the discontinuity line and the ZEL network is calculated. The $p$ and $\psi$ values at the left side of the intersection point are calculated by linear interpolation. Knowing $\omega_{0}, p$, and $\psi$ values at the left side of the intersection point, the stress $p$ and the angle $\psi$ at the right side of the intersection point are obtained. Then, the point on the wall is calculated using the equations along the ZEL lines.

For the next steps, a line with the angle $\omega_{p}(\omega$ in the previous step) is drawn from the previous inter- 
Table 1. Comparison of this study with different methods.

\begin{tabular}{|c|c|c|c|c|c|c|c|}
\hline \multirow[b]{2}{*}{$\begin{array}{c}\phi \\
(\text { degree })\end{array}$} & \multirow[b]{2}{*}{$\begin{array}{c}\delta_{w} \\
(\text { degree })\end{array}$} & \multicolumn{6}{|c|}{$\begin{array}{c}k_{a \gamma}(\text { associated flow rule, vertical wall, } \\
\left.\text { horizontal earth, } k_{h}=k_{v}=0\right)\end{array}$} \\
\hline & & $\begin{array}{l}\text { Present } \\
\text { study }\end{array}$ & $\begin{array}{c}\text { Habibagahi } \\
\text { and } \\
\text { Ghahramani }[9]\end{array}$ & $\begin{array}{l}\text { Sokolovskii } \\
\quad[2]\end{array}$ & Coulomb & $\begin{array}{c}\text { Chen } \\
\text { and Liu } \\
\text { (limit analysis) }[4]\end{array}$ & $\begin{array}{c}\text { Chen and } \\
\text { Liu (slip line) } \\
{[4]}\end{array}$ \\
\hline \multirow{2}{*}{20} & 0 & 0.49 & 0.49 & 0.49 & 0.49 & 0.49 & 0.49 \\
\hline & 10 & 0.45 & 0.40 & 0.44 & 0.44 & 0.45 & 0.45 \\
\hline \multirow{2}{*}{30} & 0 & 0.33 & 0.33 & 0.33 & 0.33 & 0.33 & 0.33 \\
\hline & 15 & 0.30 & 0.26 & 0.29 & 0.26 & 0.30 & 0.30 \\
\hline \multirow{2}{*}{40} & 0 & 0.22 & 0.22 & 0.22 & 0.22 & 0.22 & 0.22 \\
\hline & 20 & 0.20 & 0.16 & 0.19 & 0.19 & 0.20 & 0.20 \\
\hline
\end{tabular}

section point. The segment of the ZEL network that encounters with the discontinuity line is determined. This segment is divided into $n_{d}$ parts. The information on these $n_{d}$ points is calculated with the interpolation. $p$ and $\psi$ at the right side of these $n_{d}$ points are calculated. Then, the point of the mixed zone should be calculated (point $C$ ). The values of $x, z, p$ and $\psi$ of this point can be obtained from Eqs. (14)-(17). The distance between point $C$ and line between the previous intersection point and the point on the wall (for the second step) or in the mixed zone (for the third and the following steps) is calculated. Within these $n_{d}$ points, the point that has the minimum distance from the line, is selected as the exact intersection point. Knowing the information in the right side of the intersection point, the points in the mixed zone and on the wall can be obtained by using the equations along the ZEL lines. This procedure is repeated until the ZEL network is calculated completely.

\section{Results}

As mentioned before, the characteristics of the ZEL network points have been determined by a computer code. The average stress on the wall boundary $\left(p_{f}\right)$ has been specified and the $\sigma_{f}$ and $\tau_{f}$ distribution along the retaining wall have been obtained. So, the active lateral earth force has been calculated by integrating stresses and can be defined as [4]:

$$
p_{a}=\frac{1}{2} \gamma H^{2} k_{a \gamma}+q H k_{a q}-c H k_{a c},
$$

where $k_{a \gamma}, k_{a q}$, and $k_{a c}$ are the active lateral earth pressure coefficients due to the unit weight of the soil, surcharge, and soil cohesion, respectively.

To calculate $k_{a q}$, the unit weight and cohesion of the soil are considered zero. Also, the unit weight of the soil and surcharge are assumed zero to obtain $k_{a c}$. In order to calculate $k_{a \gamma}$, the cohesion of the soil and surcharge should be assumed as zero. By assuming this, the problem cannot be solved at the singularity point. Therefore, a small amount of the surcharge $(q=0.01 \mathrm{kPa})$ is assumed to calculate $k_{a \gamma}$. Then, to increase accuracy and remove the surcharge effect, $k_{a \gamma}$ is modified as:

$$
k_{a \gamma}=k_{a \gamma}^{\prime}-\frac{2 q k_{a q}}{\gamma H},
$$

where, $k_{a \gamma}$ is the exact value of the lateral earth pressure coefficient and $k_{a \gamma}^{\prime}$ is the lateral earth pressure coefficient obtained from analyzing the retaining wall with $q=0.01 \mathrm{kPa}$.

The lateral earth pressure coefficients are obtained for the retaining wall in various conditions. Table 1 shows a comparison between the method used in this paper and results of other researchers for $k_{a \gamma}$. Clearly, this study exactly has the same results as those of Chen and Liu [4]. Furthermore, this study has almost the same results as those of Habibagahi and Ghahramani [9] and the maximum error is $20 \%$. The method of Habibagahi and Ghahramani [9] is based on the simple zero extension line field that is applied to compute the direction of traction on the zero extension line in a loose sand. Overall, all methods provide the same $k_{a \gamma}$ values for the smooth retaining wall $\left(\delta_{w}=0\right)$ and a low difference is observed between ZEL method and other methods for the rough retaining wall. For the wall with $\delta_{w}$, the difference between ZEL method and other methods increases as $\phi$ and $\delta_{w}$ increase. The difference between ZEL method and Coulomb theory, for $\phi=40^{\circ}$ and $\delta_{w}=20^{\circ}$, is more than other cases.

The seismic $k_{a \gamma}$ is shown in Figure 5 for the associated flow rule $(v=\phi)$. The effects of the horizontal and vertical pseudo-static coefficients have been evaluated. $k_{a \gamma}$ increases as $k_{h}$ increases. More values of $k_{a \gamma}$ has been obtained in presence of $k_{v}$.

In addition, the analysis has been done for nonassociative soils to consider the effect of dilation angle. $k_{a \gamma}$ has been shown and compared with the numerical method of Benmeddour et al. [21] in Table 2. The 
Table 2. $k_{a \gamma}$ for the associated and non-associated flow rules and their comparison with the numerical method of Benmeddour et al. [21].

\begin{tabular}{|c|c|c|c|c|c|c|c|c|c|}
\hline \multirow[b]{4}{*}{$\begin{array}{c}\phi \\
\text { (degree) }\end{array}$} & \multirow[b]{4}{*}{$\beta / \phi$} & \multicolumn{8}{|c|}{$k_{a \gamma}\left(\right.$ vertical wall, $\left.k_{h}=k_{v}=0\right)$} \\
\hline & & \multicolumn{4}{|c|}{$\delta_{w} / \phi=0$} & \multicolumn{4}{|c|}{$\delta_{w} / \phi=0.667$} \\
\hline & & \multicolumn{2}{|r|}{$v=0$} & \multicolumn{2}{|r|}{$v=\phi$} & \multicolumn{2}{|r|}{$v=0$} & \multicolumn{2}{|r|}{$v=\phi$} \\
\hline & & $\begin{array}{c}\text { Present } \\
\text { study }\end{array}$ & $\begin{array}{c}\text { Benmeddour } \\
\text { et al., } \\
2012[21] \\
\end{array}$ & $\begin{array}{c}\text { Present } \\
\text { study }\end{array}$ & $\begin{array}{c}\text { Benmeddour } \\
\text { et al., } \\
2012[21]\end{array}$ & $\begin{array}{c}\text { Present } \\
\text { study }\end{array}$ & $\begin{array}{c}\text { Benmeddour } \\
\text { et al., } \\
2012[21] \\
\end{array}$ & $\begin{array}{c}\text { Present } \\
\text { study }\end{array}$ & $\begin{array}{c}\text { Benmeddour } \\
\text { et al., } \\
2012 \text { [21] }\end{array}$ \\
\hline \multirow{3}{*}{30} & 0 & 0.382 & 0.361 & 0.334 & 0.330 & 0.298 & 0.301 & 0.301 & 0.299 \\
\hline & -0.333 & 0.453 & 0.411 & 0.375 & 0.373 & 0.354 & 0.344 & 0.341 & 0.343 \\
\hline & -0.667 & 0.578 & 0.486 & 0.450 & 0.440 & 0.443 & 0.416 & 0.414 & 0.416 \\
\hline \multirow{3}{*}{40} & 0 & 0.298 & 0.281 & 0.218 & 0.215 & 0.219 & 0.230 & 0.202 & 0.200 \\
\hline & -0.333 & 0.417 & 0.327 & 0.247 & 0.246 & 0.266 & 0.279 & 0.231 & 0.233 \\
\hline & -0.667 & 0.495 & 0.398 & 0.302 & 0.291 & 0.350 & 0.367 & 0.286 & 0.270 \\
\hline
\end{tabular}

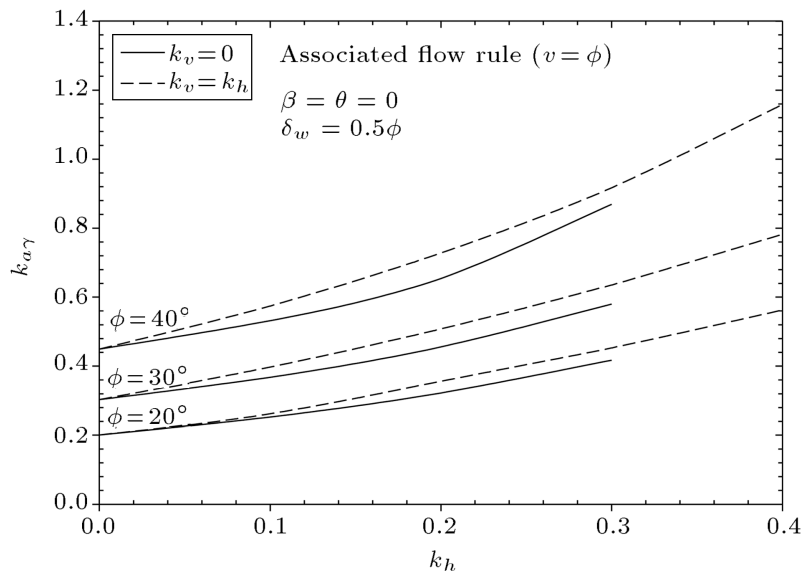

Figure 5. The effect of pseudo-static coefficients on $k_{a \gamma}$ $(\theta=0)$.

results showed that $k_{a \gamma}$ is lower for associative soils than that for the non-associative one. The maximum error between this study and the numerical method [21] is about $6 \%$ for the associated flow rule and $21 \%$ for the non-associated flow rule.

The variations of $k_{a \gamma}$ are also shown in Figure 6 $\left(\phi=30^{\circ}\right)$ and Figure $7\left(\phi=20^{\circ}\right)$ for different values of wall angle. The difference due to a 10-degrees increase in dilation angle is almost 1.93-9.62\% and 1.04-4.29\% for $\phi=30^{\circ}$ (Figure 6) and $\phi=20^{\circ}$ (Figure 7), respectively. Furthermore, the results of the analysis for different values of the ground slope are shown in Figures 8 and 9 . The difference is almost $0.42-4.62$ and 1.09-4.59 percentages for $\phi=30^{\circ}$ (Figure 8) and $\phi=20^{\circ}$ (Figure 9), respectively. The results showed that the dilation angle effect on $k_{a \gamma}$ is low for $\phi=30^{\circ}$ and $\phi=20^{\circ}$. It is obvious that for associated flow rule, $k_{a \gamma}$ decreases by increasing each of the soil friction angle, wall angle, and the ground slope parameters.

The dilation angle effect on $k_{a q}$ has been considered, as shown in Tables 3 and $4 . \quad k_{a q}$ increases as the dilation angle increases. The ranges of increase in $k_{a q}$ in Table 3 are $0.48-7.04,0.27-3.36$, and 0.15 -

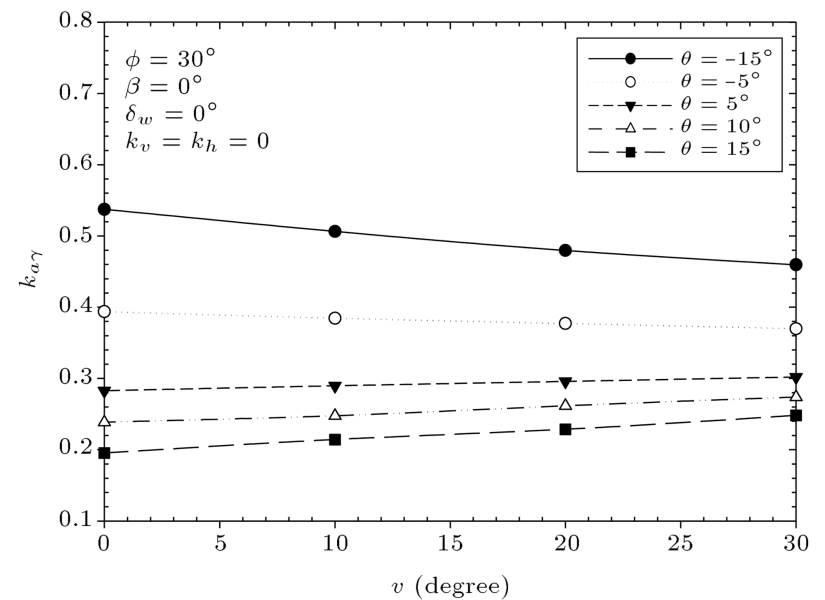

Figure 6. The dilation angle effect on $k_{a \gamma}$ for different values of wall angle in static case $\left(\phi=30^{\circ}\right)$.

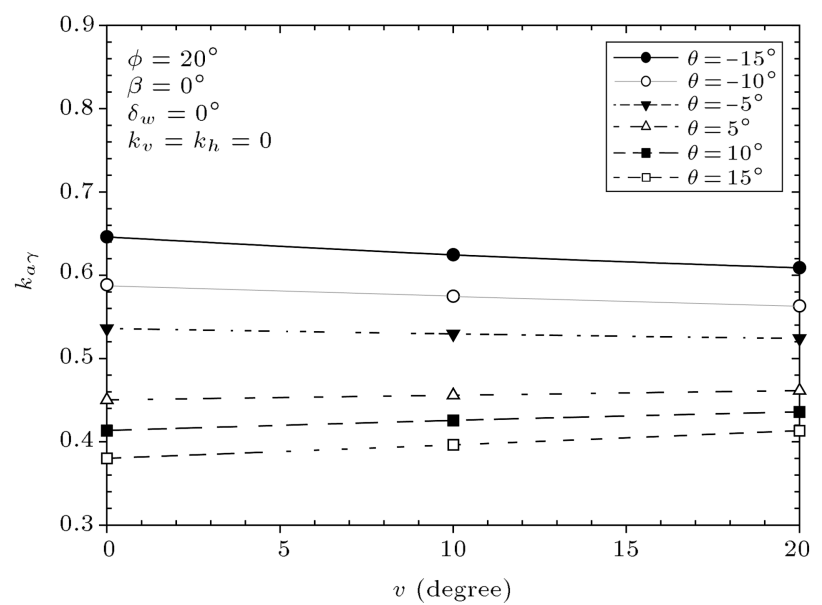

Figure 7. The dilation angle effect on $k_{a \gamma}$ for different values of wall angle in static case $\left(\phi=20^{\circ}\right)$.

1.39 percentages for soil friction angles equal to 40 , 30 , and 20 degrees, respectively. In Table 4 , the $k_{a q}$ increase ranges are 0.1-1.76, 0.13-1.61, and 0.15-1.65 percentages for soil friction angles equal to 40, 30, and 20 degrees, respectively. So, the dilation angle does not 
Table 3. The effect of dilation angle on $k_{a q}$ for different values of wall angle.

\begin{tabular}{|c|c|c|c|c|c|c|c|c|c|}
\hline \multirow{3}{*}{$\begin{array}{c}v \\
\text { (degree) }\end{array}$} & \multicolumn{9}{|c|}{$k_{a q}$ for horizontal earth, $\delta_{w}=0^{\circ}, c_{w}=0, k_{h}=k_{v}=0$} \\
\hline & \multicolumn{3}{|c|}{$\phi=45^{\circ}$} & \multicolumn{3}{|c|}{$\phi=30^{\circ}$} & \multicolumn{3}{|c|}{$\phi=20^{\circ}$} \\
\hline & $\theta=5^{\circ}$ & $\theta=10^{\circ}$ & $\theta=15^{\circ}$ & $\theta=5^{\circ}$ & $\theta=10^{\circ}$ & $\theta=15^{\circ}$ & $\theta=5^{\circ}$ & $\theta=10^{\circ}$ & $\theta=15^{\circ}$ \\
\hline 0 & 0.179 & 0.148 & 0.121 & 0.297 & 0.266 & 0.238 & 0.460 & 0.433 & 0.411 \\
\hline 10 & 0.183 & 0.154 & 0.129 & 0.300 & 0.271 & 0.246 & 0.461 & 0.437 & 0.416 \\
\hline 20 & 0.186 & 0.159 & 0.136 & 0.302 & 0.275 & 0.252 & 0.462 & 0.439 & 0.420 \\
\hline 30 & 0.188 & 0.163 & 0.142 & 0.303 & 0.277 & 0.255 & - & - & - \\
\hline 40 & 0.189 & 0.165 & 0.145 & - & - & - & - & - & - \\
\hline
\end{tabular}

Table 4. The effect of dilation angle on $k_{a q}$ for different values of ground slope.

\begin{tabular}{|c|c|c|c|c|c|c|c|c|c|}
\hline \multirow{3}{*}{$\begin{array}{c}v \\
(\text { degree })\end{array}$} & \multicolumn{9}{|c|}{$k_{a q}$ for horizontal earth, $\delta_{w}=0^{\circ}, c_{w}=0, k_{h}=k_{v}=0$} \\
\hline & \multicolumn{3}{|c|}{$\phi=40^{\circ}$} & \multicolumn{3}{|c|}{$\phi=30^{\circ}$} & \multicolumn{3}{|c|}{$\phi=20^{\circ}$} \\
\hline & $\beta=5^{\circ}$ & $\beta=10^{\circ}$ & $\beta=15^{\circ}$ & $\beta=5^{\circ}$ & $\beta=10^{\circ}$ & $\beta=15^{\circ}$ & $\beta=5^{\circ}$ & $\beta=10^{\circ}$ & $\beta=15^{\circ}$ \\
\hline 0 & 0.207 & 0.197 & 0.187 & 0.315 & 0.300 & 0.285 & 0.462 & 0.439 & 0.419 \\
\hline 10 & 0.208 & 0.199 & 0.190 & 0.317 & 0.303 & 0.290 & 0.464 & 0.443 & 0.426 \\
\hline 20 & 0.208 & 0.200 & 0.193 & 0.318 & 0.304 & 0.293 & 0.464 & 0.445 & 0.430 \\
\hline 30 & 0.209 & 0.201 & 0.195 & 0.318 & 0.305 & 0.294 & - & - & - \\
\hline 40 & 0.209 & 0.202 & 0.195 & - & - & - & - & - & - \\
\hline
\end{tabular}

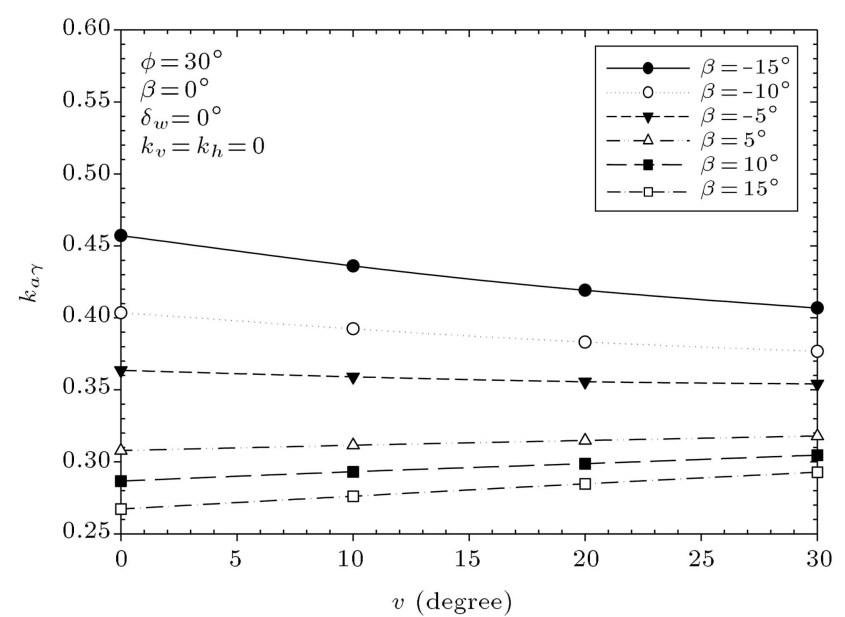

Figure 8. The dilation angle effect on $k_{a \gamma}$ for different values of ground slope in static case $\left(\phi=30^{\circ}\right)$.

affect $k_{a q}$ considerably. But, its effect is clearer for the cases in which the wall angles are not equal to zero.

Also, $k_{a c}$ has been calculated for various values of the dilation angle. The results have been shown in Tables 5 and 6 . Obviously, increasing the dilation angle leads to decrease in $k_{a c}$. In the analysis for various values of $\beta$, the maximum decreases in $k_{a c}$ are 0.92 , 1.01 and 0.94 percentages and the minimum decreases are $0.3,0.12$ and 0.11 percentages for the soil friction angles equal to 20,30, and 40 degrees, respectively. In the analysis for various values of $\theta$, the maximum decreases of $k_{a c}$ are $0.92,1.02$ and 0.94 percentages and the minimum decreases are $0.13,0.12$ and 0.11 percentages for the soil friction angles equal to 20, 30,

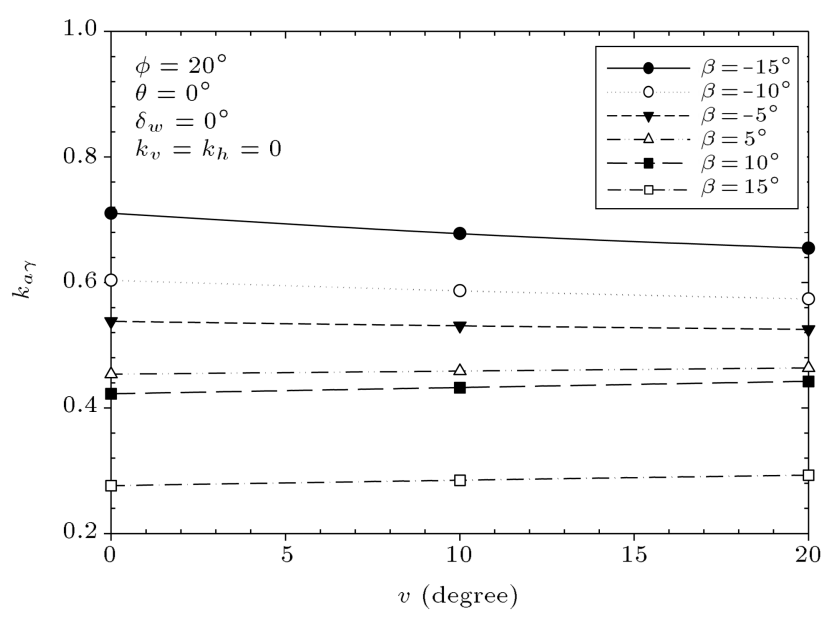

Figure 9. The dilation angle effect on $k_{a \gamma}$ for different values of ground slope in static case $\left(\phi=20^{\circ}\right)$.

and 40 degrees, respectively. So, the strongest effect of the dilation angle on $k_{a c}$ is 1.01 percentage.

For associated flow rule, the effects of the soil friction angle, wall angle, and ground slope on $k_{a q}$ (see Tables 3 and 4 ) and $k_{a c}$ (see Tables 5 and 6 ) can also be derived. $k_{a q}$ increases by decreasing each of the soil friction angle, wall angle, and ground slope parameters. $k_{a c}$ increases by decreasing the soil friction angle or ground slope and increasing the wall angle.

The effect of dilation on the dynamic lateral earth pressure coefficient, $k_{a \gamma}$, has also been considered in Figures 10 and 11 for $\phi=40^{\circ}$ and $\phi=30^{\circ}$, respectively. Similarly, Figures 12 and 13 have been provided for $k_{a q}$. The least effect of dilation angle 
Table 5. The effect of dilation angle on $k_{a c}$ for different values of wall angle.

\begin{tabular}{|c|c|c|c|c|c|c|c|c|c|}
\hline \multirow{3}{*}{$\begin{array}{c}v \\
\text { (degree) }\end{array}$} & \multicolumn{9}{|c|}{$k_{a c}$ for horizontal earth, $\delta_{w}=0^{\circ}, c_{w}=0, k_{h}=k_{v}=0$} \\
\hline & \multicolumn{3}{|c|}{$\phi=40^{\circ}$} & \multicolumn{3}{|c|}{$\phi=30^{\circ}$} & \multicolumn{3}{|c|}{$\phi=20^{\circ}$} \\
\hline & $\theta=5^{\circ}$ & $\theta=10^{\circ}$ & $\theta=15^{\circ}$ & $\theta=5^{\circ}$ & $\theta=10^{\circ}$ & $\theta=15^{\circ}$ & $\theta=5^{\circ}$ & $\theta=10^{\circ}$ & $\theta=15^{\circ}$ \\
\hline 0 & 0.983 & 1.034 & 1.090 & 1.224 & 1.299 & 1.381 & 1.495 & 1.600 & 1.716 \\
\hline 10 & 0.978 & 1.027 & 1.080 & 1.219 & 1.290 & 1.367 & 1.491 & 1.590 & 1.701 \\
\hline 20 & 0.975 & 1.021 & 1.071 & 1.216 & 1.283 & 1.358 & 1.489 & 1.585 & 1.692 \\
\hline 30 & 0.973 & 1.016 & 1.065 & 1.215 & 1.280 & 1.351 & - & - & - \\
\hline 40 & 0.972 & 1.014 & 1.061 & - & - & - & - & - & - \\
\hline
\end{tabular}

Table 6. The effect of dilation angle on $k_{a c}$ for different values of ground slope.

\begin{tabular}{|c|c|c|c|c|c|c|c|c|c|}
\hline \multirow{3}{*}{$\begin{array}{c}v \\
\text { (degree) }\end{array}$} & \multicolumn{9}{|c|}{$k_{a c}$ for vertical wall, $\delta_{w}=0^{\circ}, c_{w}=0, k_{h}=k_{v}=0$} \\
\hline & \multicolumn{3}{|c|}{$\phi=40^{\circ}$} & \multicolumn{3}{|c|}{$\phi=30^{\circ}$} & \multicolumn{3}{|c|}{$\phi=20^{\circ}$} \\
\hline & $\beta=-15^{\circ}$ & $\beta=-10^{\circ}$ & $\beta=-5^{\circ}$ & $\beta=-15^{\circ}$ & $\beta=-10^{\circ}$ & $\beta=-5^{\circ}$ & $\beta=-15^{\circ}$ & $\beta=-10^{\circ}$ & $\beta=-5^{\circ}$ \\
\hline 0 & 1.053 & 1.019 & 0.979 & 1.334 & 1.279 & 1.219 & 1.658 & 1.576 & 1.490 \\
\hline 10 & 1.043 & 1.011 & 0.975 & 1.321 & 1.270 & 1.215 & 1.643 & 1.566 & 1.485 \\
\hline 20 & 1.035 & 1.005 & 0.971 & 1.311 & 1.264 & 1.212 & 1.634 & 1.561 & 1.483 \\
\hline 30 & 1.029 & 1.001 & 0.969 & 1.305 & 1.260 & 1.210 & - & - & - \\
\hline 40 & 1.025 & 0.998 & 0.968 & - & - & - & - & - & - \\
\hline
\end{tabular}

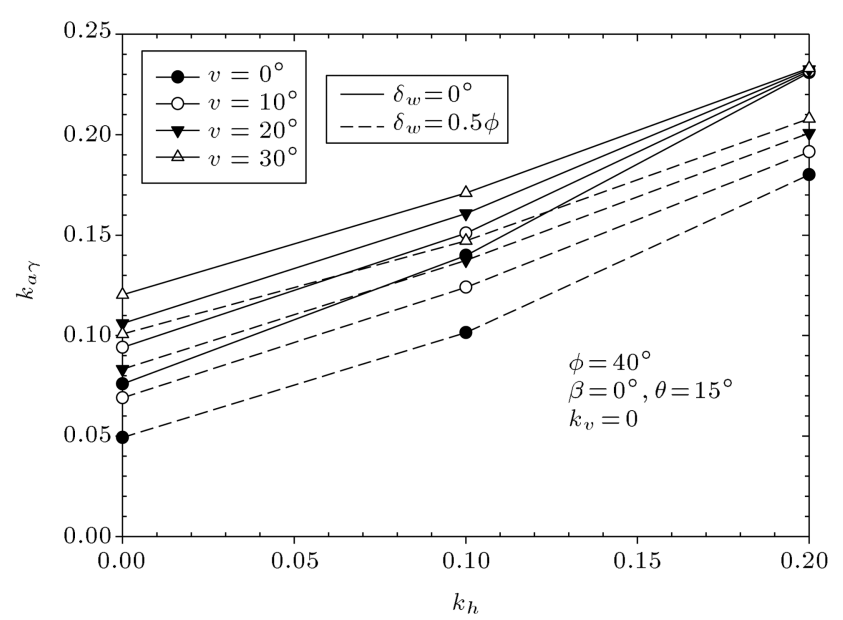

Figure 10. The dilation angle effect on $k_{a \gamma}$ in dynamic case $\left(\phi=40^{\circ}\right)$.

is observed for $k_{h}$ equal to 0.2 . In this case, the $k_{a \gamma}$ increase ranges from 0.26 to 0.94 percentages for the smooth wall and from 0.54 to 5.95 percentages for the rough wall. Also, the $k_{a q}$ increase changes from 0.09 to $2.38 \%$ for smooth wall, and from 0.14 to $2.6 \%$ for rough wall. The maximum increases of $k_{a \gamma}$ and $k_{a q}$ are observed for $\phi=40^{\circ}$ and $k_{h}=0$ by increasing the dilation angle from zero to 10 degrees. The results showed that this maximum increase of $k_{a \gamma}$ is $19.34 \%$ and $28.7 \%$ for the smooth and rough wall, respectively. Furthermore, this maximum increase of $k_{a q}$ is $6.57 \%$ and $9.72 \%$ for the smooth and rough wall, respectively. It is clear that the dilation angle affects $k_{a \gamma}$ more than $k_{a q}$ and the lateral earth

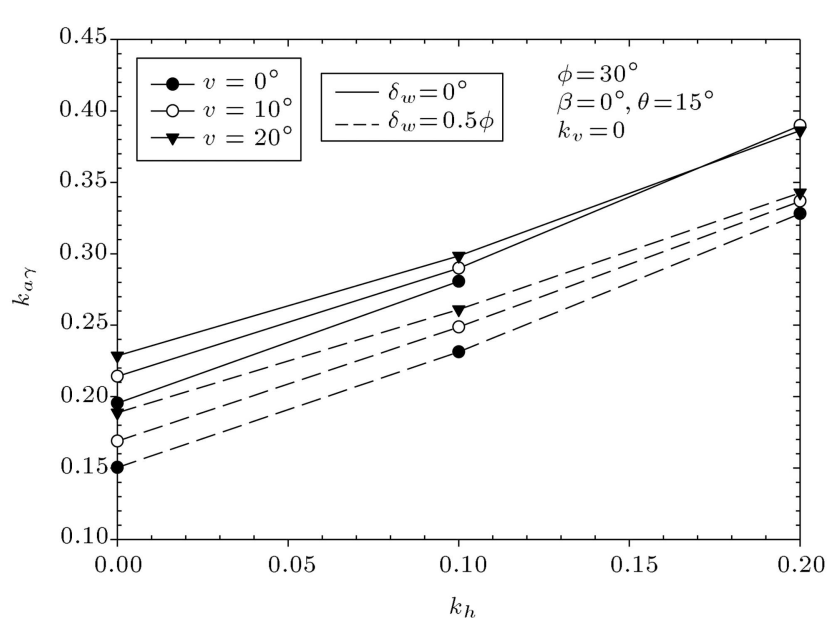

Figure 11. The dilation angle effect on $k_{a \gamma}$ in dynamic case $\left(\phi=30^{\circ}\right)$.

pressure coefficients for the rough wall are more than the lateral earth pressure coefficients for the smooth wall.

The dilation angle also affects the failure zone of the retaining wall. Figures 14 and 15 show the effect of the dilation angle on the failure surface for the smooth wall for $\phi=40^{\circ}$ and $30^{\circ}$, respectively. Also, Figures 16 and 17 have been prepared for the rough wall $\left(\delta_{w}=\phi\right)$. As shown, the extent of the failure zone decreases as the dilation angle increases. The dilation effect is the strongest for soil with the internal friction angle equal to 40 degrees. In this case, the extent of failure zone (at the ground surface) decreases from 3 to 1.40 meters for smooth wall $\left(\delta_{w}=0\right)$ and 


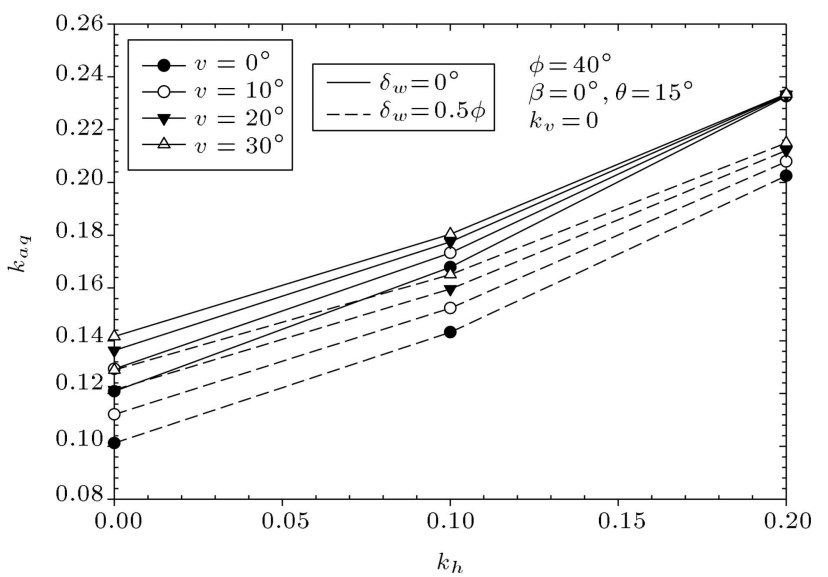

Figure 12. The dilation angle effect on $k_{a q}$ in dynamic case $\left(\phi=40^{\circ}\right)$.

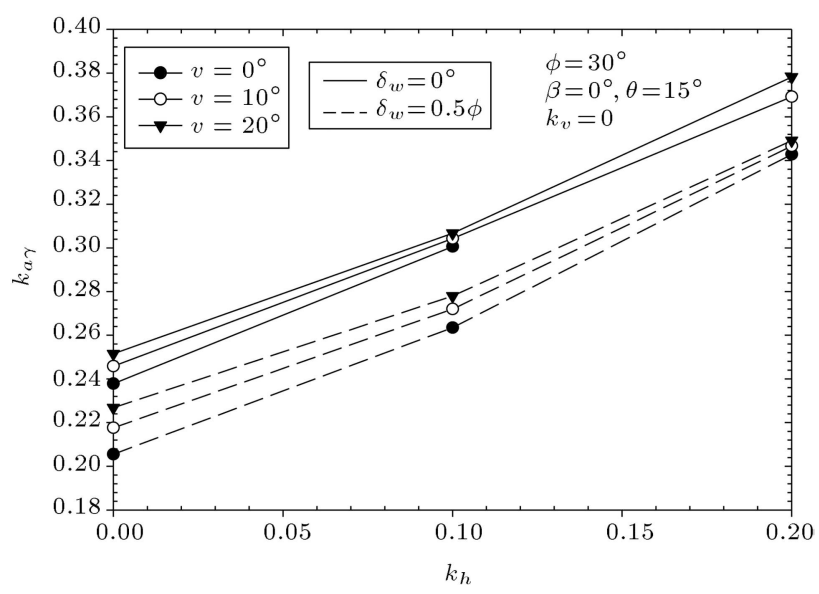

Figure 13. The dilation angle effect on $k_{a q}$ in dynamic case $\left(\phi=30^{\circ}\right)$.

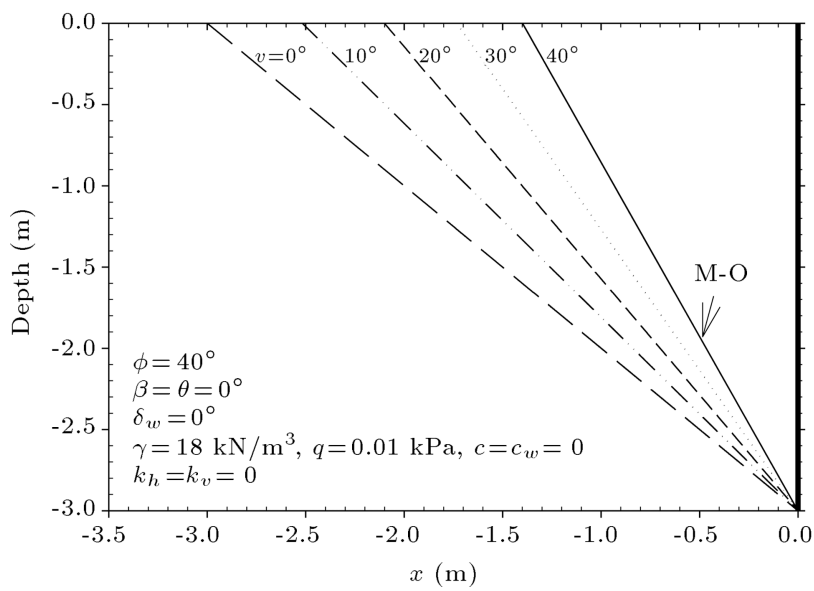

Figure 14. The dilation angle effect on the failure zone $\left(\phi=40^{\circ}, \delta_{w}=0\right)$.

from 3.48 to 1.59 meters for rough wall $\left(\delta_{w}=\phi\right)$. Considering the dilation effect on the failure zone shows that the dilation angle affects the failure zone considerably and is more effective for rough retaining walls. The Monobe-Okabe (M-O) failure surfaces [24]

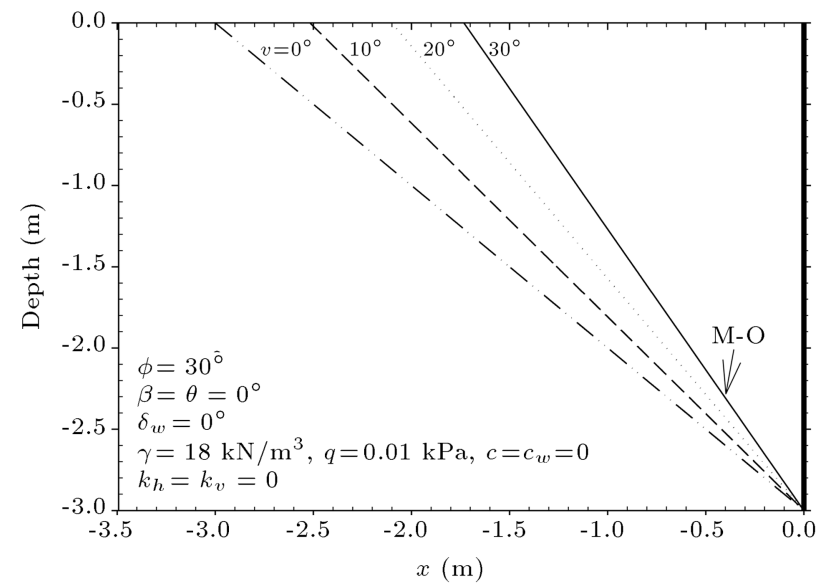

Figure 15. The dilation angle effect on the failure zone $\left(\phi=30^{\circ}, \delta_{w}=0\right)$.

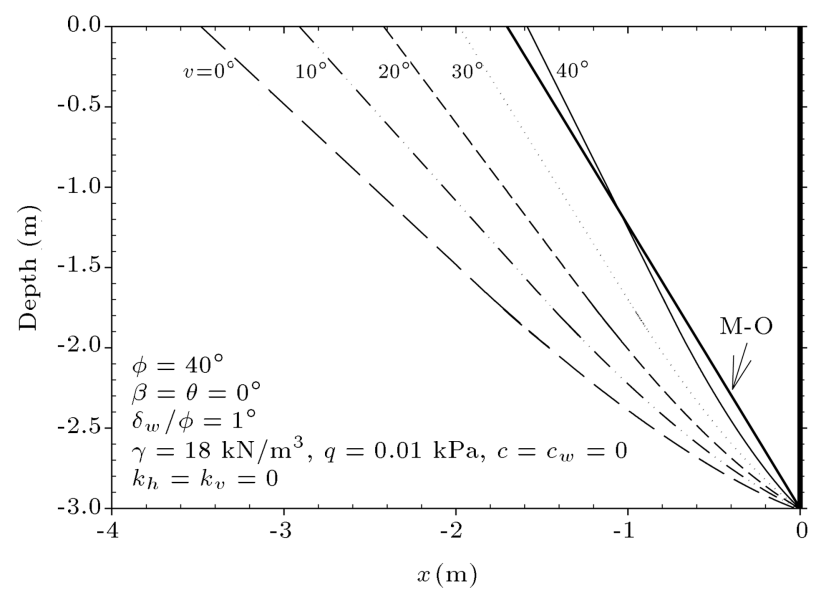

Figure 16. The dilation angle effect on the failure zone $\left(\phi=40^{\circ}, \delta_{w}=\phi\right)$.

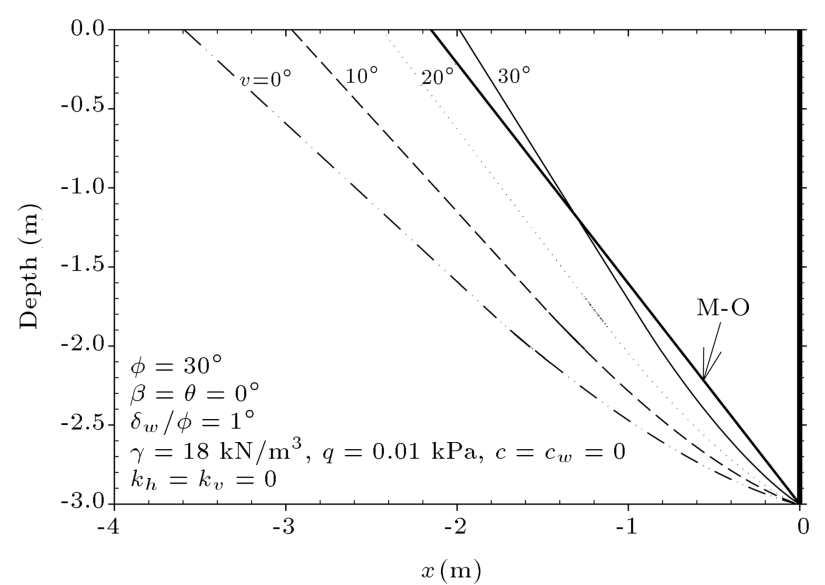

Figure 17. The dilation angle effect on the failure zone $\left(\phi=30^{\circ}, \delta_{w}=\phi\right)$.

are also shown in the Figures 14-17. As shown, for smooth walls, the M-O and associated ZEL failure surfaces are the same; but for rough walls, the failure surfaces are not linear and the M-O and associated ZEL failure surfaces are somewhat different. 


\section{Conclusions}

In order to evaluate the lateral earth pressure on the retaining walls, the static and seismic lateral earth pressure coefficients have been calculated using the method of zero extension lines. The results of the lateral earth pressure coefficients due to the soil unit weight, surcharge, and soil cohesion are presented for associated and non-associated flow rules. The lateral earth pressure coefficients were found to be compatible with other methods. A low difference between ZEL method and other methods is observed and the difference is equal to zero in many cases. The influence of the different parameters on the lateral earth pressure coefficients has been explored.

For associative soils, $k_{a \gamma}$ and $k_{a q}$ decrease by increasing each of the soil friction angle, wall angle, and ground slope parameters, and $k_{a \gamma}$ decreases by increasing the soil-wall interface friction angle. Also, increasing the soil friction angle and ground slope and decreasing the wall angle decrease $k_{a c}$. The seismic lateral earth pressure coefficient $k_{a \gamma}$ for associative soils increases as the horizontal and vertical pseudo-static coefficients increase.

For non-associative soils, the dilation angle affects the lateral earth pressure coefficients, slightly. By increasing the dilation angle, $k_{a \gamma}$ increases for plus values of the wall angle and ground slope, and decreases for minus values of the wall angle and ground slope; $k_{a c}$ decreases and $k_{a q}$ increases. The dilation angle effect on the failure zone of the retaining wall is such that the extent of the failure zone in active case decreases considerably as the dilation angle increases. The dilation angle effects on $k_{a \gamma}, k_{a q}$, and the failure zone of the retaining wall for the rough wall are more than those for the smooth wall.

\section{Nomenclature}

$\theta$

$H$

$c$

$\phi$ $p$

$\psi$

$p_{0}$

$\psi_{0}$

$p_{f}$

$\psi_{f}$

$f_{x}, f_{z}$

$k_{h}, k_{v}$

$d \varepsilon^{+}, d \varepsilon^{-}$

$k_{a \gamma}$

$k_{a q}$

$k_{a c}$

\section{Average stress}

Angle between $\sigma_{1}$ and the horizontal axis

Average stress on the ground surface

The angle $\psi$ on the ground surface

Average stress on the wall

The angle $\psi$ on the wall

Body forces along $x$ and $z$ directions

Horizontal and vertical pseudo-static earthquake coefficients

Lengths of plus and minus zero extension lines

Lateral earth pressure coefficient due to the unit weight of the soil

Lateral earth pressure coefficient due to the surcharge

Lateral earth pressure coefficient due to the cohesion of the soil

\section{References}

1. Peng, M. and Chen, J. "Slip-line solution to active earth pressure on retaining walls", Géotechnique, 63(12), pp. 1008-1019 (2013).

2. Sokolovskii, V., Statics of Soil Media, Scienc. Publ., Butterworth, London (1960).

3. Askari, F., Totonchi, A. and Farzaneh, O. "Application of admissible stress fields for computation of passive seismic force in retaining walls", Sci. Iran, 19(4), pp. 967-973 (2012).

4. Chen, W. and Liu, X. "Limit analysis in soil mechanics", Developments in Geotechnical Engineering (1990).

5. Iskander, M., Chen, Z., Omidvar, M., Guzman, I. and Elsherif, O. "Active static and seismic earth pressure for $c-\phi$ soils", Soils Found., 53(5), pp. 639-652 (2013).

6. Lin, Y.L., Leng, W.M., Yang, G.L., Zhao, L.H., Li, L. and Yang, J.S. "Seismic active earth pressure of cohesive-frictional soil on retaining wall based on a slice analysis method", Soil Dyn. Earthquake Eng., 70, pp. 133-147 (2015).

7. Roscoe, K.H. "The influence of strains in soil mechanics", Geotechnique, 20(2), pp. 129-170 (1970).

8. James, R. and Bransby, P. "A velocity field for some passive earth pressure problems", Geotechnique, 21(1), pp. 61-83 (1971).

9. Habibagahi, K. and Ghahramani, A. "Zero extension line theory of earth pressure", J. Geotech. Eng. Div., 105(7), pp. 881-896 (1979).

10. Anvar, S. and Ghahramani, A. "Equilibrium equations on zero extension lines and its application to soil 
engineering", Iran J. Sci. Technol., 21(1), pp. 11-34 (1997).

11. Jahanandish, M. "Development of a zero extension line method for axially symmetric problems in soil mechanics", Sci. Iran, 10(2), pp. 203-210, Elsevier (2003).

12. Jahanandish, M. and Keshavarz, A. "Evaluation of static and dynamic stability of slopes by the zero extension line method", in Fourth International Conference of Earthquake Engineering and Seismology, SEE4, Tehran, Iran (2003).

13. Jahanandish, M., Mansourzadeh, S. and Emad, K. "Zero extension line method for three-dimensional stability analysis in soil engineering", Iran J. Sci. Technol. B, 34(B1), pp. 63-80 (2010).

14. Jahanandish, M., Veiskarami, M. and Ghahramani, A. "Investigation of foundations behavior by implementation of a developed constitutive soil model in the ZEL method", Int. J. Civ. Eng., 9(4), pp. 293-306 (2011).

15. Behpoor, L. and Ghahramani, A. "Zero extension line theory of static and dynamic bearing capacity", in Frac, Hüft Asian Regional Conference on Soil Mechanics and Foundation Engineering (1987).

16. Behpoor, L. and Ghahramani, A. "Recommendation for evaluation of dynamic earth pressure on retaining structures for Iranian earthquake code", in Second International Seminar on Soil Mechanics and Foundation Engineering of Iran, Shiraz University, Iran (1993).

17. Behpoor, L. and Ghahramani, A. "Undrained bearing capacity of clay by zero extension line", in Proceedings of the International Conference on Soil Mechanics and Foundation Engineering - International Society for Soil Mechanics and Foundation Engineering, A.A. Balkema (1994).

18. Veiskarami, M., Jahanandish, M. and Ghahramani, A. "Prediction of foundations behaviors by a stress level based hyperbolic soil model and the ZEL method", Computational Methods in Civil Engineering, 1(1), pp. 37-54 (2010).

19. Veiskarami, M., Jahanandish, M. and Ghahramani, A. "Application of the ZEL method in the prediction of foundation bearing capacity considering the stress level effect", Soil Mech. Found. Eng., 47(3), pp. 75-85 (2010).

20. Veiskarami, M., Jahanandish, M. and Ghahramani, A. "Prediction of the bearing capacity and loaddisplacement behavior of shallow foundations by the stress-level-based ZEL method", Sci. Iran, 18(1), pp. 16-27 (2011).

21. Benmeddour, D., Mellas, M., Frank, R. and Mabrouki, A. "Numerical study of passive and active earth pressures of sands", Comput. Geotech., 40, pp. 34-44 (2012).

22. Lee, I. and Herington, J. "A theoretical study of the pressures acting on a rigid wall by a sloping earth or rock fill", Geotechnique, 22(1), pp. 1-26 (1972).

23. Shiau, J. and Smith, C. "Numerical analysis of passive earth pressures with interfaces", in Proceedings of the III European Conference on Computational Mechanics (ECCM 2006), Springer-Verlag (2006).

24. Kramer, S.L., Geotechnical Earthquake Engineering, Prentice Hall, New Jersey (1996).

\section{Appendix}

The parameters in Eqs. (14)-(17) are:

$$
\begin{aligned}
& \operatorname{tgmp}=\frac{\tan \left(\psi_{C}+\zeta_{C}\right)+\tan \left(\psi_{B}+\zeta_{B}\right)}{2} \\
& \operatorname{tgmm}=\frac{\tan \left(\psi_{C}-\zeta_{C}\right)+\tan \left(\psi_{A}-\zeta_{A}\right)}{2} \\
& A_{3}=p_{B}-p_{A}+A_{1}+\psi_{B} B_{m p}-B_{m m} \psi_{A}-A_{2} \\
& A_{4}=B_{m p}-B_{m m}
\end{aligned}
$$

where:

$$
\begin{aligned}
& B_{m p}=\left(\bar{\alpha}+\bar{\zeta} \frac{B C}{A C}\right)\left[\left(p_{C}+p_{B}\right) \tan \phi+2 c\right], \\
& A_{1}=C_{m p}+D_{m p}, \\
& C_{m p}=f_{x} \bar{\beta}\left[\left(x_{C}-x_{B}\right) \bar{\alpha}-\left(z_{C}-z_{B}\right) \tan \phi\right], \\
& D_{m p}=f_{z} \bar{\beta}\left[\left(x_{C}-x_{B}\right) \tan \phi+\left(z_{C}-z_{B}\right) \bar{\alpha}\right], \\
& B_{m m}=-\left(\bar{\alpha}+\bar{\zeta} \frac{A C}{B C}\right)\left[\left(p_{C}+p_{A}\right) \tan \phi+2 c\right], \\
& A_{2}=C_{m m}+D_{m m}, \\
& C_{m m}=f_{x} \bar{\beta}\left[\left(x_{C}-x_{A}\right) \bar{\alpha}-\left(z_{C}-z_{A}\right) \tan \phi\right], \\
& D_{m m}=f_{z} \bar{\beta}\left[-\left(x_{C}-x_{A}\right) \tan \phi+\left(z_{C}-z_{A}\right) \bar{\alpha}\right] .
\end{aligned}
$$

\section{Biographies}

Amin Keshavarz is currently an Assistant Professor of Civil Engineering in the School of Engineering at Persian Gulf University, Iran. He received his BSc degree in Civil Engineering from Persian Gulf University in 1997. He also received his MSc and $\mathrm{PhD}$ degrees in Civil Engineering (Soil Mechanics and Foundations) from Shiraz University, Iran, in 2000 and 2007, respectively. His research interests are stress characteristics and ZEL methods, soil dynamics and geotechnical earthquake engineering, and stability 
analysis of reinforced and unreinforced soil slopes and retaining walls.

Zahra Pooresmaeil received her BSc degree in Civil Engineering from Persian Gulf University, Iran, in 2011. She was accepted for MSc degree in 2012. Her field of study was Soil Mechanics and Foundations. In 2014, she attended the 2nd Iranian Conference on Geotechnical Engineering and the 8th National Congress on Civil Engineering and presented some parts of her thesis. She received her MSc degree from Persian Gulf University in 2014. 